\title{
Does ispaghula husk stimulate the entire colon in diverticular disease?
}

\author{
H A Thorburn, K B Carter, J A Goldberg, I G Finlay
}

\begin{abstract}
The effect of ispaghula husk on colonic motility of the right and left side was examined in 10 patients with left sided diverticular disease using an untethered pressure sensitive radiotelemetry capsule. After treatment, ispaghula husk reduced mouth to rectum transit by a median of 8.8 hours and the time to midtransverse colon by five hours. In the right colon there was an increase in the median percentage activity of $7 \%$ and the median number of pressure waves $>5 \mathrm{~mm} \mathrm{Hg} /$ hour rose by $35 \cdot 3$. Motility changes in the left colon were less pronounced. Five of the seven patients with abdominal pain and six of the nine patients with altered bowel habit responded to treatment. These results suggest that it is ispaghula husk's action on the right unaffected colon which alleviates the symptoms of left sided diverticular disease.
\end{abstract}

University Department of Surgery, Glasgow Royal Infirmary

H A Thorburn

J A Goldberg

I G Finlay

Department of Clinical Physics and Bioengineering, 11 West Graham Street, Glasgow K B Carter

Correspondence to: Ms H A Thorburn, University Department of Surgery, Glasgow Royal Infirmary, Glasgow Royal Infirmary, Glasgow G31 2ER.

Glasgow G31 2ER. 3 June 1991

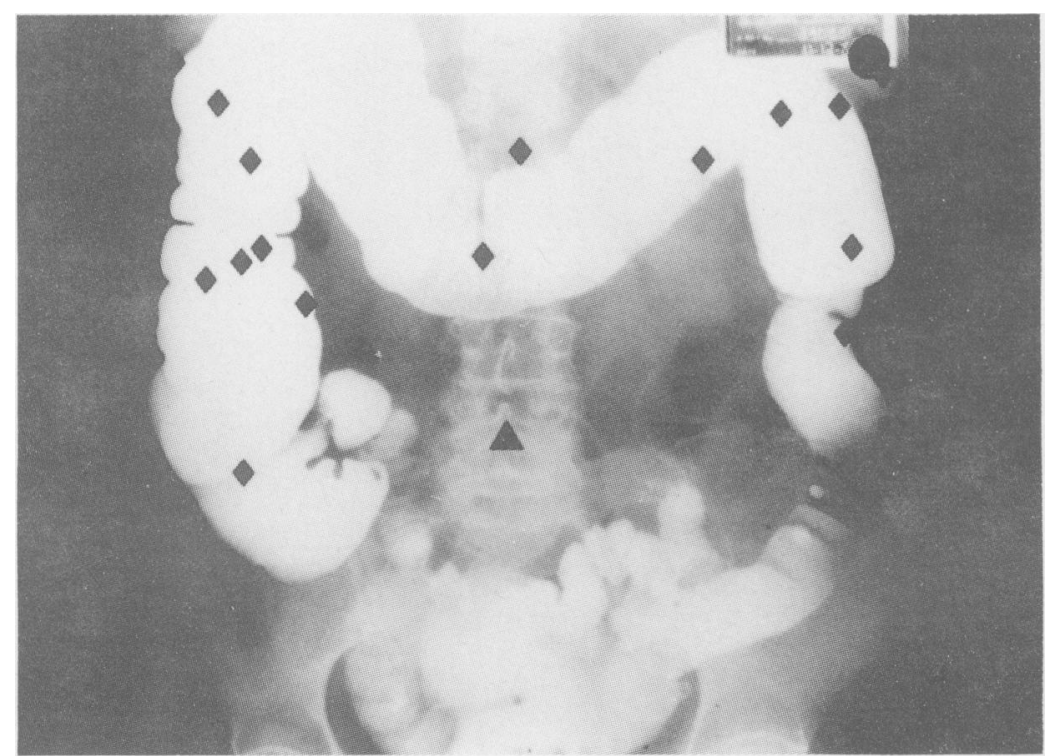

Figure 1: Plots of radiopill position showing its progression through the colon. $\mathbf{\Delta}$ umbilicus; colon. fibre diets have been advocated for both treatment and prevention of the disorder. ${ }^{+7}$ High fibre therapy is often prescribed as a commercial preparation such as ispaghula husk and has been shown to improve symptoms in patients with diverticular disease. The mode of action of these preparations in the treatment of diverticular disease is uncertain. ${ }^{8-10}$

We have developed a computer based analysis system for use with traditional radiotelemetry pressure capsules. ${ }^{11-12}$ This has been used to study the effect of ispaghula husk on colonic motility in diverticular disease.

\section{Methods}

PATIENTS

Ten patients, six men (median age 62.5 years, range 50-79) and four women (median age 69.5 years, range 59-73) were studied with symptoms attributable to large bowel disease and in whom diverticula were present in the left colon on barium enema. The patients were receiving no medication known to affect colonic motility.

All patients were admitted to hospital the day before study and their symptoms documented. Abdominal pain was recorded according to an ordered category scale (absent, mild, moderate, severe). Bowel habit was also noted (constipated, normal, diarrhoea).

Each patient was studied in a single bedded room in which they were free to move. The normal hospital diet was provided in the room.

A pressure sensitive radiopill (Type 7014,

Remote Control Systems Ltd.) was calibrated at $37 \pm 1^{\circ} \mathrm{C}$ against a mercury manometer, sealed in a plastic finger stall and then swallowed by the subject at $10.30 \mathrm{pm}$ on the evening of admission. At 8.30 am the following morning, the trolley mounted system consisting of a radiotelemetry receiver (Type 7060, Remote Control Systems Ltd) linked to an Atari 1040ST microcomputer with its visual display unit, was taken to the patient. The system, which has been described and assessed in a separate publication,,$^{13}$ picked up signals from the radiopill through a belt aerial worn around the patient's abdomen ${ }^{1+}$; decoded these frequency modulated signals in the receiver; and stored the decoded signals in the Atari's memory. During a motility study colonic pressure was displayed as a waveform on the monitor. An alarm sounded if the signal level fell below an acceptable value. This facilitated the positioning of the aerial at the start of a run and alerted the patient to adjust the belt during the course of the study.

The localisation of the radiopill within the gastrointestinal tract was determined by the use of a modified field strength meter (Remote Control Systems Ltd) comprising a detector box and rod aerial. This registered the strength of the radiofrequency signal emitted by the radiopill, maximum needle deflection corresponding to the closest approach to the pill. This technique was validated in the laboratory and found to locate the radiopill to within $10 \mathrm{~mm} .{ }^{15}$ During the clinical studies, the rod aerial was moved across the patient's abdomen and the point of maximum needle deflection marked with a cross. Each cross was numbered and the time of each 


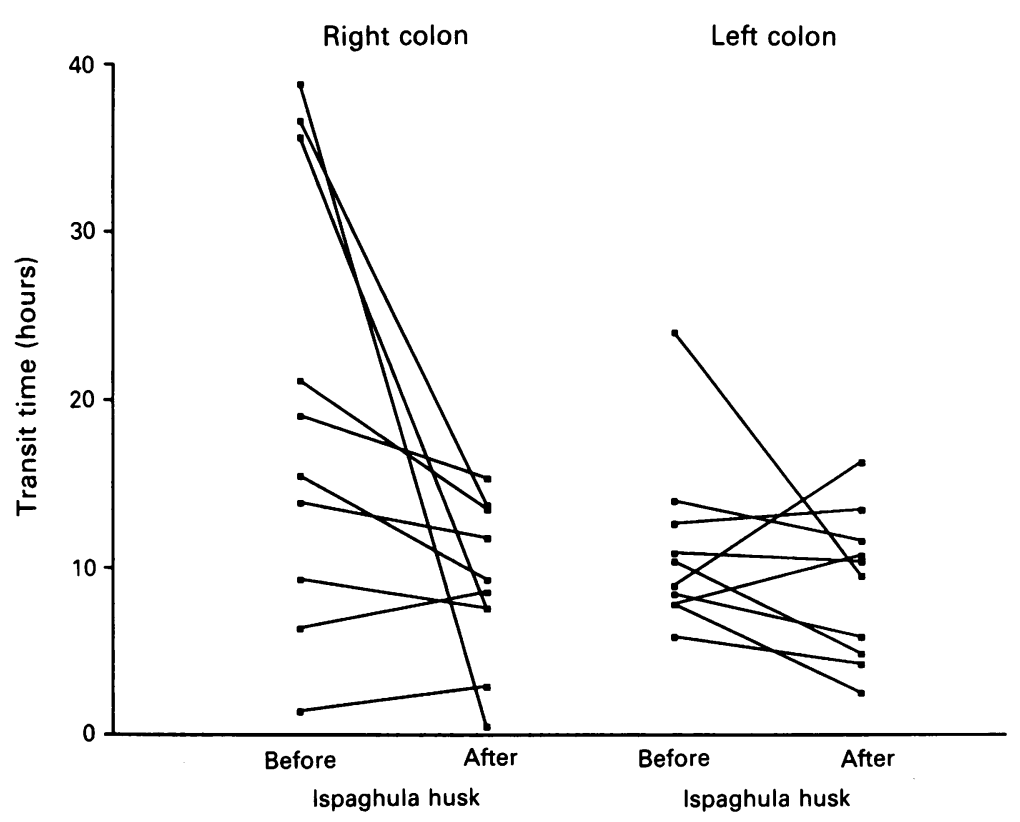

Figure 2: Transit time through the right and left colon before and after treatment with ispaghula husk (Fybogel). enabled the following parameters to be analysed when the radiopill was in the right and left colon.

(1) motility index $=$

$\frac{2 \times \text { area under pressure curve } \times 100}{\text { measurement time (hours) }}$

(2) \% activity (the percentage of the total recording time during which pressure waves were above a threshold value of $5 \mathrm{~mm} \mathrm{Hg}$ )

(3) Total number of peaks greater than 5 $\mathrm{mm} \mathrm{Hg}$ /hour

(4) Total number of peaks greater than 50 $\mathrm{mm} \mathrm{Hg}$ /hour.

\section{STATISTICAL ANALYSIS}

For each parameter the Wilcoxon's signed-rank test was used to examine the effect of ispaghula husk. Results are expressed as median (range). The median change (range) is also given, together with $95 \%$ confidence intervals derived from the Wilcoxon's signed-rank test.

\section{Results}

Four weeks treatment with ispaghula husk significantly reduced mouth to rectum transit by decreasing the time taken to reach the midtransverse colon (Table I). The effect of ispaghula husk on individual transit times for the right colon (estimated) and the left colon is shown in Figure 2.

Details of the motility parameters for the patients are given in Figures 3-6. In the right colon there was a significant increase in percentage activity and the number of pressure waves above $5 \mathrm{~mm} \mathrm{Hg} /$ hour (Table II). No significant changes were shown in the left colon after treatment.

Symptomatic changes after treatment are shown in Table III. Of the seven patients complaining of abdominal pain, five improved on ispaghula husk. Bowel habit improved in six of the nine patients who initially reported this as troublesome.

\section{Discussion}

Ispaghula husk has been shown to alleviate symptoms in patients with diverticular disease but the pharmacological action is uncertain..$^{8-10}$ Transit time may increase or decrease after treatment. ${ }^{8-10}$ Similarly, basal colonic motility measured by open ended tubes in the distal colon has been found to either increase ${ }^{8}$ or decrease. ${ }^{9}$

The present study using radiotelemetry found that ispaghula husk reduces mouth to rectum transit time predominantly by decreasing the

TABLE I Effect of ispaghula husk on transit times in 10 patients with diverticular disease

\begin{tabular}{|c|c|c|c|c|c|}
\hline Transit time & $\begin{array}{l}\text { Pretreatment median } \\
\text { (range) } \text { (hours) }\end{array}$ & $\begin{array}{l}\text { Post treatment } \\
\text { median (range) } \\
\text { (hours) }\end{array}$ & $\begin{array}{l}\text { Difference }{ }^{\star} \text { median } \\
\text { (range) (hours) }\end{array}$ & $\begin{array}{l}95 \% \text { confidence } \\
\text { interval }\end{array}$ & pvalue \\
\hline $\begin{array}{l}\text { Mouth to rectum } \\
\text { Mouth to mid-transverse colon } \\
\text { Right colon } \dagger \\
\text { Left colon }\end{array}$ & $\begin{array}{l}34 \cdot 3(23 \cdot 0-67 \cdot 6) \\
25 \cdot 2(9 \cdot 4-46 \cdot 8) \\
17 \cdot 2(1 \cdot 4-38 \cdot 8) \\
9 \cdot 6(5 \cdot 8-24 \cdot 0)\end{array}$ & $\begin{array}{l}23 \cdot 7(18 \cdot 8-35 \cdot 0) \\
16 \cdot 9(8 \cdot 5-23 \cdot 3) \\
8 \cdot 9(0 \cdot 5-15 \cdot 3) \\
9 \cdot 9(2 \cdot 5-16 \cdot 3)\end{array}$ & $\begin{array}{l}-8 \cdot 8(-42 \cdot 6 \rightarrow 9 \cdot 8) \\
-5 \cdot 0(-38 \cdot 3 \rightarrow 2 \cdot 2) \\
-5 \cdot 0(-38 \cdot 3 \rightarrow 2 \cdot 2) \\
-2 \cdot 0(-14 \cdot 5 \rightarrow 7 \cdot 5)\end{array}$ & $\begin{array}{l}-25 \cdot 0 \text { to }-1 \cdot 0 \\
-21 \cdot 0 \text { to }-1 \cdot 1 \\
-21 \cdot 0 \text { to }-1 \cdot 1 \\
-5 \cdot 8 \text { to } 1.9\end{array}$ & $\begin{array}{l}0.03 \ddagger \\
0.03 \ddagger \\
0.03 \ddagger \\
0.31\end{array}$ \\
\hline
\end{tabular}

^Difference calculated as 'post' - 'pre' values for each patient; †Entry into caecum taken as 8 hours post ingestion; $¥$ Statistically significant $(p<0.05)$. 


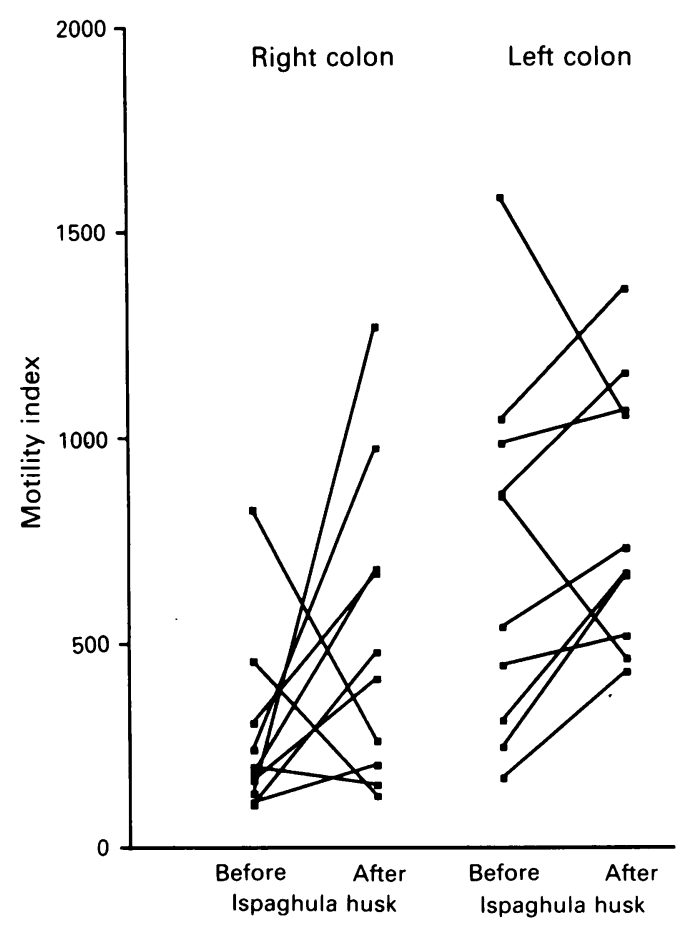

Figure 3: Motility index of the right and left colon before and after treatment with ispaghula husk (Fybogel).

duration of right colonic transit. Transit through the left colon was unaffected. 'Right colonic transit,' however, may have included a component from small bowel as mouth to caecum transit was estimated to be eight hours. ${ }^{16}$ The action of ispaghula husk may, therefore, be in either distal small bowel, right colon or both.

The possibility of small bowel activity being included in the motility analysis, however, is less likely. In 15 of the telemetry studies, clinical considerations dictated that monitoring began 10 hours post-ingestion when the radiopill was located at or beyond the right iliac fossa and a pressure waveform characteristic of large bowel was obtained. In the five remaining runs where

TABLE II Effect of ispaghula husk on the motility parameters of the right and left colon in 10 patients with diverticular disease

\begin{tabular}{|c|c|c|c|}
\hline Parameter & $\begin{array}{l}\text { Difference } \\
\text { median-range }\end{array}$ & $95 \%$ confidence interval & p-value \\
\hline $\begin{array}{l}\text { Right motility index } \\
\text { Left motility index } \\
\text { Right \% activity } \\
\text { Left } \% \text { activity } \\
\text { Right peaks }>5 \mathrm{~mm} \mathrm{Hg} / \mathrm{h} \\
\text { Left peaks }>5 \mathrm{~mm} \mathrm{Hg} / \mathrm{h} \\
\text { Right peaks }>50 \mathrm{~mm} \mathrm{Hg} \mathrm{h} \\
\text { Left peaks }>50 \mathrm{~mm} \mathrm{Hg} / \mathrm{h}\end{array}$ & $\begin{array}{c}306(-560 \rightarrow 1137) \\
223(-531 \rightarrow 419) \\
7 \cdot 0(-3 \cdot 0 \rightarrow 34 \cdot 0) \\
2 \cdot 5(-8 \cdot 0 \rightarrow 22 \cdot 0) \\
35 \cdot 3(-24 \cdot 1 \rightarrow 121 \cdot 8) \\
9 \cdot 7(-36 \cdot 3 \rightarrow 79 \cdot 2) \\
0 \cdot 6(-3 \cdot 6 \rightarrow 11 \cdot 2) \\
2 \cdot 7(-2 \cdot 0 \rightarrow 12 \cdot 7)\end{array}$ & $\begin{array}{r}-98 \text { to } 614 \\
-136 \text { to } 324 \\
2.0 \text { to } 19.5 \\
-1.0 \text { to } 12.0 \\
9.0 \text { to } 76.9 \\
-15.4 \text { to } 44.7 \\
-0.7 \text { to } 5.2 \\
-0.3 \text { to } 9.3\end{array}$ & $\begin{array}{l}0.15 \\
0.36 \\
0 \cdot 01 \dagger \\
0.08 \\
0 \cdot 01 \dagger \\
0.42 \\
0 \cdot 15 \\
0.08\end{array}$ \\
\hline
\end{tabular}

^Difference calculated as 'post' - 'pre' values for each patient; $†$ Statistically significant $(p<0.05)$.

TABLE III Effect of ispaghula husk on abdominal pain and bowel habit in 10 patients with diverticular disease

\begin{tabular}{lllll}
\hline $\begin{array}{l}\text { Patient } \\
\text { no }\end{array}$ & $\begin{array}{l}\text { Abdominal } \\
\text { pain }\end{array}$ & $\begin{array}{l}\text { Change on } \\
\text { ispaghula husk }\end{array}$ & $\begin{array}{l}\text { Altered bowel } \\
\text { habit }\end{array}$ & $\begin{array}{l}\text { Change on } \\
\text { ispaghula husk }\end{array}$ \\
\hline 1 & Yes & Improved & Yes & Improved \\
2 & Yes & Improved & Yes & Improved \\
3 & No & Unchanged & Yes & Improved \\
4 & Yes & Unchanged & Yes & Unchanged \\
5 & No & Unchanged & Yes & Unchanged \\
6 & Yes & Improved & Yes & Improved \\
7 & Yes & Worse & Yes & Unchanged \\
8 & Yes & Improved & No & Unchanged \\
9 & No & Unchanged & Yes & Improved \\
10 & Yes & Improved & Yes & Improved \\
\hline
\end{tabular}

observations were able to be made from the time of ingestion, the radiopill was found to have reached the right colon by 11 hours. The exact time of entry into large bowel was difficult to determine, however, as the changes in pressure waveform through the ileocaecal valve were gradual rather than abrupt as has been reported before. ${ }^{1718}$ Therefore, by examining traces 10 hours after ingestion of the radiopill the amount of ileal activity included in the analysis was minimised.

The changes in motility parameters mirrored the transit results in that ispaghula husk had a more pronounced effect on the motility of the right colon. This was mainly apparent in the increased number of contractions above $5 \mathrm{~mm} \mathrm{Hg} /$ hour in the right colon, accompanied by an increase in percentage activity. Although left colonic activity and the number of high amplitude peaks did increase after treatment with ispaghula husk, this was not large enough to reach statistical significance.

This study was facilitated by the availability of the computer analysis system for use with traditional pressure sensitive radiotelemetry capsules. It had the advantage over other techniques for measuring colonic motility in that there was no bowel preparation, no invasive instrumentation with patient stress, and only minimal restriction of patient movement. It also allowed non-invasive analysis of the right colon. Although the capsule has limitations, in particular the fact that it cannot distinguish propulsive from segmental activity, this may be a minor limitation because mass movements of colonic contents occur infrequently. ${ }^{19}$

It has been shown that food ${ }^{20-23}$ and sleep ${ }^{1924}$ influence colonic motility. Therefore, as the radiopill progressed through the bowel it would have been subjected to periods of prandial stimulation and motor quiescence. On examina-

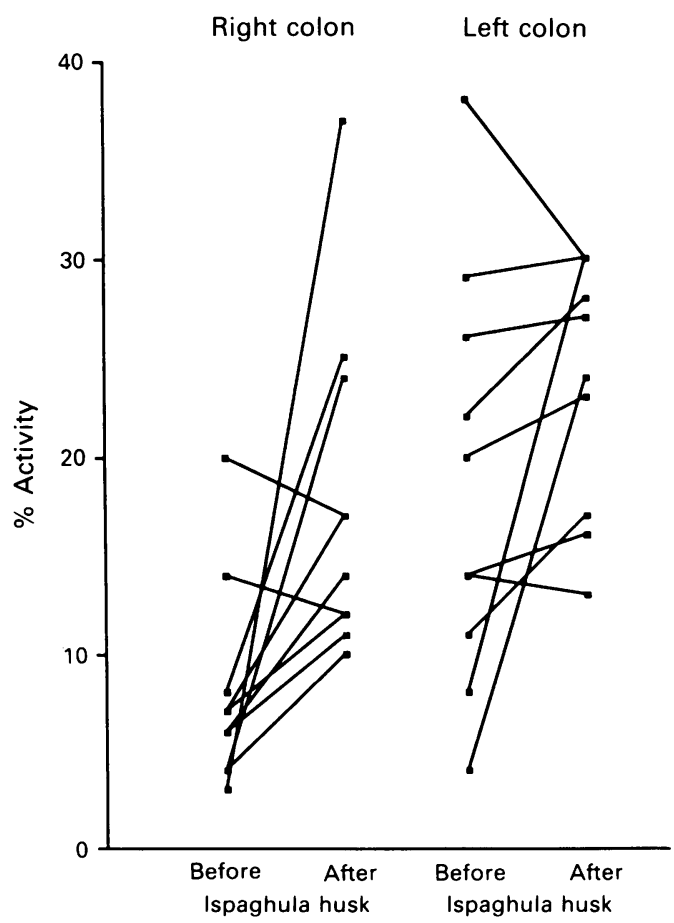

Figure 4: Percentage activity of the right and left colon before and after treatment with ispaghula husk (Fybogel). 


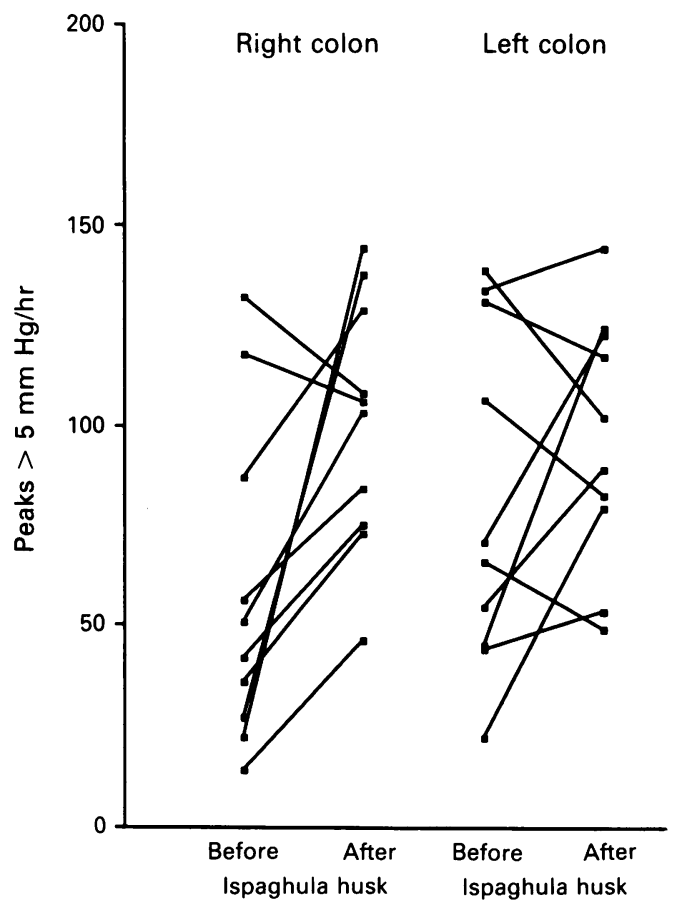

Figure 5: Peaks $>5 \mathrm{~mm} \mathrm{Hg} /$ hour of the right and left colon before and after treatment with ispaghula husk (Fybogel).

tion of patient records, however, we found that our results could not be attributed to differences in either the number of meals or the duration of sleep.

The motility of the right hemicolon has received little attention because of its relative inaccessibility. In two studies, however, with pressure sensors in both sides of the colon, right and left colonic motility in healthy volunteers was found to be similar. ${ }^{25} 26$ In addition, measurements from a radiotelemetry pressure capsule did not detect differences in motility index as it progressed through the normal colon. ${ }^{15}$ In the present study of left sided diverticular disease, this balance in motility appears to be disturbed.

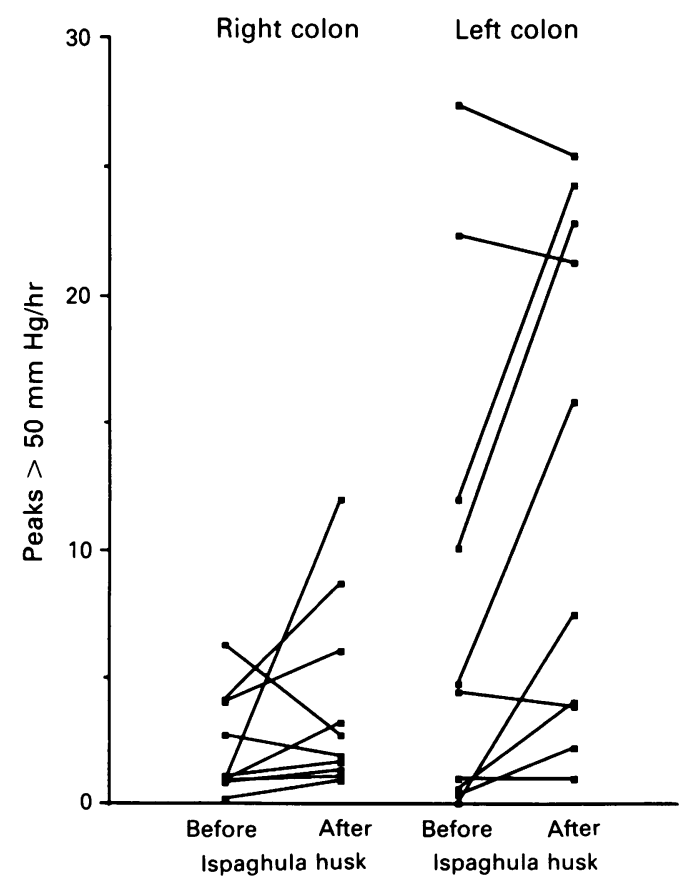

Figure 6: Peaks $>50 \mathrm{~mm} \mathrm{Hg} /$ hour of the right and left colon before and after treatment with ispaghula husk (Fybogel).
This lends support to the view that the diseased hemicolon is more active than its unaffected half. ${ }^{27}$

The results of the present study raise a number of questions. First, how does ispaghula husk stimulate the right colon? Possible explanations include simple mechanical stimulation of the mucosal receptors by fibre particles similar to that observed in a study of plastic particles by Tomlin and Read. ${ }^{28}$ This may occur in either the ileum, caecum, or both. Alternatively, there may be fermentation of ispaghula in the colon $^{29}$ producing distension with a resultant increase in motility.

Second, does ispaghula husk damage the diverticular colon? After four weeks of treatment, this study did not find a significant increase in the high pressure colonic contractions, thought to contribute to the formation of pulsion diverticula. ${ }^{30}$ Localised areas of high pressure activity may have been present, however, but their contribution to colonic activity in either hemicolon must have been too small to produce a significant change. Ispaghula husk's primary effect in the present study was to increase the number of low amplitude contractions on the right side of the colon which had no radiological evidence of diverticula.

Third, why do the symptoms in patients with diverticular disease respond to ispaghula husk? In agreement with Eastwood et al, ${ }^{8}$ we found that ispaghula husk improved the symptoms of diverticular disease without reducing activity in the diseased left colon. In this disorder there may be some symptomatic relief attributable to a placebo effect. ${ }^{1031}$ It was, therefore, not surprising that there was no apparent relationship between the modification of symptoms and changes in motility after treatment. This study, however, has shown that ispaghula husk primarily stimulated the right, unaffected colon and accelerated the movement of intestinal contents to the midtransverse region. Perhaps it is this reduction in transit, producing a softer less viscous stool for passage through the diseased side, which contributes most to symptomatic improvement.

The authors thank Frank Toal and Robert Rennie, University Department of Anaesthesia, Glasgow Royal Infirmary, for their coputing expertise. We also than Dr Gordon Murray University Department of Surgery, for his statistical advice. This study was supported by a grant from Reckitt and Colman, Hull.

1 Painter NS, Burkitt DP. Diverticular disease of the colon, 20th century problem. Clin Gastroenterol 1975; 4: 53-69.

2 Almy TP, Howell DA. Diverticular disease of the colon. NEngl'f Med 1980; 302: 324-31.

3 Cranston D, McWhinnie D, Collin J. Dietary fibre and gastrointestinal disease. Br $\mathcal{F}$ Surg 1988; 75: 508-12.

4 Findlay JM, Smith AN, Mitchell WD, Anderson AJB, Eastwood MA. Effects of unprocessed bran on colon function in normal subjects and in diverticular disease. Lance 1974; i: 146-9.

5 Painter NS. The high fibre diet in the treatment of diverticular disease of the colon. Postgrad Med F 1974; 50: 629-35.

6 Brodribb AJM, Humphreys DM. Diverticular disease: three studies, Part II - Treatment with bran. BMF 1976; 1: 425-8.

Gear JSS, Ware A, Fursdon P, et al. Symptomless diverticular disease and intake of dietary fibre. Lancet 1979; i: 511-4.

8 Eastwood MA, Smith AN, Brydon WG, Pritchard J. Comparison of bran, ispaghula, and lactulose on colonic function parison of bran, ispaghula, and lactulose on col

9 Archbold A, Parks TG. Fybogel; its effect on colonic motility and intestinal transit in diverticular disease. Ir $\mathcal{F} \mathrm{Med} S \mathrm{Ci}$ and intestinal $1979 ; 148: 27$.

10 Ornstein MH, Littlewood ER, McLean Baird I, Fowler J, North WRS, Cox AG. Are fibre supplements really necessary in diverticular disease of the colon? A controlled clinical trial. BMF 1981; 282: 1353-6. 
11 Wolff HS. The radiopill. New Scientist 1961; 261: 419-21. 12 Connell AM, McCall J, Misiewicz JJ, Rowlands EN. Observations on the clinical use of radio pills. BMF 1963; 2: 771-4.

13 Thorburn HA, Carter KB, Goldbers JA, Finlay IG. Remote Control Systems' Radiotelemetry Receiver 7060: its use in clinical colonic motility measurement. $\mathcal{F}$ Med Eng Techno

14 Carter KB, Thorburn HA, Finlay IG, Goldberg JA. Novel multidirectional aerial for 'nearfield telemetry'. Med Bio Eng Comput 1989; 27: 631-4.

15 Thorburn HA. A radiotelemetry study of colonic motility in patients with diverticular disease. [MSc Thesis]. Glasgow: University of Glasgow, 1989.

16 Kirwan WO, Smith AN. Gastrointestinal transit estimated by an isotope capsule Scand F Gastroenterol 1974; 9: 763-6.

17 Connell AM, Rowlands EN. Wireless telemetering from the digestive tract. Gut 1960; 1: 266-72.

18 Reynolds JR, Evans DF, Clarke AG, Hardcastle JD. Twentyfour hour colonic motility patterns in normal ambulant subjects. Fournal of Ambulatory Monitoring 1989; 2: 303-12.

9 Narducci F, Bassotti G, Gaburri M, Morelli A. Twenty four hour manometric recording of colonic motor activity in hour manometric recording of

20 Hertz AF. Constipation and allied intestinal disorders. London: Oxford Medical Publications, 1909.

21 Christensen J. The response of the colon to eating. Am $\mathcal{f}$ Clin Nutr 1985; 42: 1025-32

22 Trotman IF, Misiewicz JJ. Sigmoid motility in diverticular disease and the irritable bowel syndrome. Gut 1988; 29: 218-22.

23 Moreno-Osset E, Bazzocchi S, Lo S, et al Association between postprandial changes in colonic intraluminal pressure and transit. Gastroenterology 1989; 96: 1265-73.

24 Rosenblum MJ, Cummins AJ. The effect of sleep and of amytal on the motor activity of the human sigmoid colon. Gastroenterology 1954

25 Misiewicz JJ, Connell AM, Pontes FA. Comparison of the effect of meals and prostigmine on the proximal and distal colon in patients with and without diarrhoea. Gut 1966; 7: 468-73.

26 Kerlin P, Zinsmeister A, Phillips S. Motor responses to food of the ileum, proximal colon, and distal colon of healthy humans. Gastroenterology 1983; 84: 762-70.

27 Sugihara K, Muto T, Morioka Y. Motility study in right sided diverticular disease of the colon. Gut 1983; 24: 1130-4.

28 Tomlin J, Read NW. Laxative properties of indigestible plastic particles. $B M \mathcal{F}$ 1988; 297: 1175-6.

29 Cummings JH, Englyst HN. Fermentation in the human large intestine and the available substrates. Am $\mathcal{F}$ Clin Nutr 1987 ; 45: 1243-55.

30 Painter NS, Truelove SC, Ardran GM, Tuckey M. Segmentation and the localization of intraluminal pressures in the human colon, with special reference to the pathogenesis of colonic diverticula. Gastroenterology 1965; 49: 169-77.

31 Hodgson WJB. The placebo effect. Am $\mathcal{F}$ Gastroenterol 1977; 67: 157-62. 